\title{
COMPARISON OF SEVOFLURANE VERSUS PROPOFOL FOR TRACHEAL INTUBATION IN CHILDREN
}

\author{
Zulfiqar Ali, Azhar, Aamer Mahmood Malak, Arslan, Saqib, Anjum Qadri \\ Combined Military Hospital Multan/National University of Medical Sciences (NUMS) Pakistan
}

\begin{abstract}
Objective: To compare the quality of intubation and hemodynamic response in children undergoing endotracheal intubation facilitated with propofol versus sevoflurane.

Study Design: Quasi-experimental study.

Place and Duration of Study: Department of Anesthesia, Combined Military Hospital Multan, from Aug 2018 to Apr 2019. Methodology: A total number of 112 children planned for tracheal intubation were included in this randomized controlled trial. Patients were randomly allocated into two equal groups. In group P (propofol) patient's 2.5-3.0 mg/kg propofol was given before insertion of endotracheal tube and in group S (sevoflurane) patients $8.0 \%$ sevoflurane with $100 \% \mathrm{O}_{2}$. Quality of intubation was assessed in all children at the time of intubation. Hemodynamic response of patients was also noted before induction of anesthesia, immediately after intubation and after 5 minutes of intubation.

Results: Mean age of children included in this study was $2.11 \pm 0.80$ years. Quality of intubation was excellent in 51 (91.1\%) patients in propofol group and in $38(67.9 \%)$ patients in sevoflurane group ( $p$-value 0.009). Mean HR after 5 minutes of intubation in group S and group P $111.98 \pm 5.43$ beats/min versus $109.05 \pm 5.99$ beats/min with $p$-value 0.008 . Mean arterial pressure after 3 minutes of intubation mean arterial pressure in group $S$ and $\mathrm{P}$ was $74.58 \pm 4.45 \mathrm{mmHg}$ versus $71.0 \pm 3.90 \mathrm{~mm}$ $\mathrm{Hg}$ with $p$-value $<0.001$. After 5 minutes of intubation mean arterial pressure in group $\mathrm{S}$ and $\mathrm{P}$ was $73.16 \pm 4.13 \mathrm{mmHg}$ versus $68.61 \pm 4.07 \mathrm{mmHg}$ with $p$-value $<0.001$.

Conclusion: Sevoflurane was found to be associated with less changes in hemodynamic parameters as compared to propofol but quality of intubation conditions was poor using sevoflurane. Propofol is a better drug as compared to sevoflurane for providing better intubation conditions.
\end{abstract}

Keywords: Tracheal intubation, Sevoflurane, Propofol, Tracheal Intubation.

This is an Open Access article distributed under the terms of the Creative Commons Attribution License (https://creativecommons.org/licenses/by-nc/4.0/), which permits unrestricted use, distribution, and reproduction in any medium, provided the original work is properly cited.

\section{INTRODUCTION}

Endotracheal intubation is routinely assisted by the use of depolarizing muscle relaxants (DMRs) such as succinylcholine ${ }^{1}$. Succinylcholine administration in children is associated with risk of arrhythmias, and malignant hyperthermia in some cases $^{2,3}$. In children, even the use of DMRs is associated with adverse events e.g. prolonged duration of neuromuscular blockage, need of reversal and inability to reverse neuromuscular blockage quickly if tracheal intubation is not possible ${ }^{4}$. To overcome complications of DMRs, alternative methods of muscle relaxants such as propofol and inhalation using sevoflurane are used for facilitation of ETT insertion in children. Propofol has a rapid onset of action and has shorter half-life. However, propofol administration has been shown to be associated with pain at the time of injection and limb movement during induction ${ }^{5}$. Inhalation anesthetics such as Sevoflurane can also be used as an alternative to facilitate tracheal intubation ${ }^{6}$.

Correspondence: Dr Zulfiqar Ali, Department of Anaesthesiology, Combined Military Hospital, Multan Pakistan

Received: 28 Aug 2019; revised received: 11 Oct 2019; accepted: 18 Oct 2019
Some studies have concluded that endotracheal intubation facilitated with Sevoflurane provide better quality of intubation as compared to propofol 7,8 . But on the other hand, Darji et al concluded that quality of intubation according to Cooper's score is better with propofol $(93.3 \%)$ versus only $80 \%$ with sevoflurane 9 . This study also found better hemodynamic control in terms of heart rate and mean arterial pressure (MAP) saturation in sevoflurane group as compared to propofol group. Like mean pulse rate just after intubation was $119.1 \pm 6.7$ beats per minute in propofol group and $114 \pm 11.8$ beats per minutes in sevoflurane group. And mean arterial pressure (MAP) was $84.6 \pm 10.8 \mathrm{mmHg}$ in sevoflurane group and $73.1 \pm 6.2 \mathrm{mmHg}$ in propofol group 9 . But quality of intubation was better in propofol group. Thwaits et al also found similar results and concluded that propofol is better than sevoflurane for endotracheal intubation in children ${ }^{9}$. In that study quality of tracheal intubation according to Copenhagen Consensus Conference (CCC) score was excellent in 82\% children receiving propofol and only $55 \%$ in children receiving sevoflurane ${ }^{10}$.

The purpose of the proposed study is to compare the quality of endotracheal intubation and hemo- 
dynamic response facilitated with propofol versus sevoflurane in children. Because propofol and sevoflurane are both commonly used for endotracheal intubation. And literature has mixed evidence regarding superiority of one drug over the other. So there is a need to conduct this study to evaluate which of the drug is better for endotracheal intubation.

\section{METHODOLOGY}

A total number of 112 children having age 1-3 years, who were planned for any surgical procedure under general anesthesia were included in this randomized controlled trial. Children with upper respiratory tract infections, in whom endotracheal intubation (ETT) was done in emergency conditions and known to be allergic to any of the study drugs were excluded. Sample size for this study is calculated by taking expected frequency of excellent quality of intubation in $82 \%$ children using propofol versus in $55 \%$ children using sevoflurane ${ }^{9}$. Level of significance (a) $5.0 \%$ and power of test (1- $\beta$ ) $80 \%$, the calculated sample size is 106 patients and we took 112 patients for this study.

Ethical approval from IRB of Combined Military Hospital Multan was taken. Informed consent from guardians of each children was taken before inclusion. The study duration was August 2018 to April 2019.

Patients were divided into two groups before insertion of endotracheal tube using envelop based draw randomization. Patients were divided into group $\mathrm{P}$ and group $\mathrm{S}$ depending upon the folded paper chosen by them. Group P; these patients received propofol for insertion of endotracheal tube. Group S; these patients received sevoflurane for insertion of endotracheal tube. All endotracheal intubations were done by a senior consultant anesthetist having at-least 5 years of post-fellowship experience. All patients were premedicated with IV and Midazolam $0.02 \mathrm{mg} / \mathrm{kg} .10$ minutes before surgery. In group P patient's 2.5 to 3.0 $\mathrm{mg} / \mathrm{kg}$ propofol was given before insertion of endotracheal tube in 30 seconds and in group $S$ patients $8.0 \%$ sevoflurane with $100 \% \mathrm{O}_{2}$ at gas flow of 6.0 liters. Sevoflurane was continued till the end of intubation. During endotracheal intubation the quality of intubation was evaluated using Copenhagen Consensus Conference (CCC) score for Assessment of Quality of Intubation (table-I).

Hemodynamic response such as changes in mean arterial pressure (MAP) and heart rate was also noted before induction of anesthesia, immediately after intubation and after 5 minutes of intubation.
Data analysis was carried out using SPSS-20. Quality of intubation between the groups was compared by using Chi-square test. Independent sample ttest was applied to determine changes in heart rate and MAP at different time intervals between the groups. A $p$-value $\leq 0.05$ was taken as significant association.

\section{RESULTS}

Out of 112 children, there were 62 (55.36\%) female children and only 50 (44.64\%) male children. Mean age of children included in this study was $2.11 \pm 0.80$ years (range 1-3 years). Most of the children were having ASA status I, $110(98.21 \%)$ children were of ASA status I and only $2(1.79 \%)$ children were of ASA status II.

On comparison of quality of intubation between the groups, quality of intubation was excellent in 51 $(91.1 \%)$ patients in propofol group and in $38(67.9 \%)$ patients in sevoflurane group ( $p$-value 0.009).

On comparison of HR between the groups, Mean $\mathrm{HR}$ there was no significant difference in baseline HR, and HR after 3 minutes. After 5 minutes of intubation, HR was $111.98 \pm 5.43$ beats $/ \mathrm{min}$ in group $S$ versus $109.05 \pm 5.99$ beats $/ \mathrm{min}$ in group $\mathrm{P}$ ( $p$-value 0.008$)$. On comparison of MAP between the groups, baseline MAP was similar between the groups, MAP after 3 minutes was was $74.58 \pm 4.45 \mathrm{mmHg}$ in group $S$ versus $71.0 \pm 3.90 \mathrm{mmHg}$ in group $\mathrm{P}(p$-value $<0.001)$. After 5 minutes, MAP was $73.16 \pm 4.13 \mathrm{mmHg}$ in group $\mathrm{S}$ versus $68.61 \pm 4.07 \mathrm{mmHg}$ in group $\mathrm{P}(p$-value $<0.001)$ (table-II).

Table-I: Copenhagen consensus conference (CCC) score for Assessing of quality of intubation.

\begin{tabular}{|c|c|c|c|}
\hline Laryngoscopy & Easy & Fair & Difficult \\
\hline \multicolumn{4}{|l|}{ Vocal Cords } \\
\hline Position & Abducted & Intermediate & Closed \\
\hline Movement & None & Moving & Closing \\
\hline \multicolumn{4}{|c|}{ Reaction to Intubation } \\
\hline Limbs & None & Slight & Vigorous \\
\hline \multirow[t]{2}{*}{ Coughing } & None & Diaphragm & $>10 s$ \\
\hline & Excellent & Good & Poor \\
\hline \multicolumn{4}{|c|}{$\begin{array}{l}\text { Clinically Acceptable: Excellent }=\text { all score excellent, Good = all scores } \\
\text { excellent or good } \\
\text { Clinically Unacceptable: Poor }=\text { any score poor }\end{array}$} \\
\hline \multicolumn{4}{|c|}{$\begin{array}{l}\text { Table-II: Comparison of quality of intubation in } \\
\text { sevoflurane versus propofol group. }\end{array}$} \\
\hline $\begin{array}{l}\text { Quality of } \\
\text { Intubation }\end{array}$ & $\begin{array}{l}\text { Propofol } \\
\text { Group } \\
\text { (Group I) }\end{array}$ & $\begin{array}{l}\text { Sevoflurane } \\
\text { Group } \\
\text { (Group II) }\end{array}$ & $\begin{array}{c}p \text { - } \\
\text { value }\end{array}$ \\
\hline Excellent & $51(91.1 \%)$ & $38(67.9 \%)$ & \multirow{3}{*}{0.009} \\
\hline Good & $04(7.1 \%)$ & $16(28.6 \%)$ & \\
\hline Poor & $01(1.8 \%)$ & $02(3.6 \%)$ & \\
\hline
\end{tabular}


Table-III: Comparison of mean heart rate and mean arterial pressure (MAP) at different intervals.

\begin{tabular}{|c|c|c|c|c|}
\hline & & $\begin{array}{c}\text { At } \\
\text { Baseline }\end{array}$ & $\begin{array}{c}\text { At } 3 \\
\text { minutes }\end{array}$ & $\begin{array}{c}\text { At } 5 \\
\text { minutes }\end{array}$ \\
\hline \multirow{2}{*}{$\begin{array}{l}\text { Mean } \\
\text { Heart } \\
\text { Rate }\end{array}$} & Sevoflurane & $\begin{array}{c}113.58 \pm \\
5.45\end{array}$ & $\begin{array}{c}114.19 \pm \\
5.11\end{array}$ & $\begin{array}{c}111.98 \pm \\
5.43\end{array}$ \\
\hline & Propofol & $\begin{array}{c}114.75 \pm \\
5.24\end{array}$ & $\begin{array}{c}112.89 \pm \\
4.96\end{array}$ & $\begin{array}{c}109.05 \pm \\
5.99\end{array}$ \\
\hline \multicolumn{2}{|c|}{$p$-value } & 0.25 & 0.17 & 0.008 \\
\hline \multirow{2}{*}{ MAP } & Sevoflurane & $\begin{array}{c}76.69 \pm \\
4.25\end{array}$ & $\begin{array}{c}74.58 \pm \\
4.45\end{array}$ & $\begin{array}{c}73.16 \pm \\
4.13\end{array}$ \\
\hline & Propofol & $\begin{array}{c}77.07 \pm \\
4.47\end{array}$ & $\begin{array}{c}71.00 \pm \\
3.90\end{array}$ & $\begin{array}{c}68.61 \pm \\
4.07\end{array}$ \\
\hline \multicolumn{2}{|c|}{$p$-value } & 0.65 & $<0.001$ & $<0.001$ \\
\hline
\end{tabular}

\section{DISCUSSION}

Introduction of newer anesthetic drugs, such as propofol and sevoflurane has minimized the need for muscle relaxants for ETT insertion in pediatric population. Sevoflurane belongs to inhalation halogenated anesthetics with low blood solubility. Sevoflurane is very less pungent and does not causes irritation of airway that makes it very suitable for induction in children ${ }^{11-13}$. A study by Inomata et al evaluated the end tidal concentration of sevoflurane for sevoflurane and found MACEI of $2.69 \%$, the authors concluded that sevoflurane is a suitable alternate for tracheal intubation and there is no need to use muscle relaxants $^{14}$. Propofol has a shorted induction time thereby provides smooth and rapid induction and hence rapid recovery. It also reduces muscle tone and thereby reduces laryngeal reflexes that makes it suitable for tracheal intubation without using muscle relaxants ${ }^{15,16}$.

This study was undertaken in 110 children of ASA 1 in the age group of 1-3 years. We found that quality of intubation was better in propofol group as compared to the sevoflurane group. Quality of intubation was excellent in $51(91.1 \%)$ patients in group Pversus in 38 (67.9\%) patients in group S.

A study by Reddy et al reported good intubating conditions in $30 \%$ patients and excellent in $43.3 \%$ patients using propofol and using sevoflurane they found good intubating conditions in $10 \%$ patients and excellent in $83.3 \%$ sevoflurane. The authors also reported excellent intubating conditions in $43.3 \%$ patients and good in $30 \%$ patients in propofol group versus excellent intubating conditions in $83.3 \%$ patients and good in $10 \%$ patients in sevoflurane plus propofol group. Reddy et al also reported similar results ${ }^{17}$.

In present study we also noted hemodynamic response to intubation in our study, heart rate reduced first after induction and then increased after intu- bation. We found significantly higher increase in heart rate in sevoflurane as compared to propofol group. Similar result were reported by Vitanen et al, they also found reduction in HR after induction and increase in $\mathrm{HR}$ after intubation, but the rise in HR was more in sevoflurane as compared to propofol group ${ }^{18}$.

In our study, mean arterial BP was decreased after induction and after intubation in both groups. However, reduction in MAP was more in propofol group as compared to sevoflurane group. A study by Thwaities et al also reported similar results they reported a mean reduction of MAP of about $20 \mathrm{mmHg}$ in propofol group as compared to nearly $10 \mathrm{mmHg}$ in sevoflurane group ${ }^{10}$.

\section{CONCLUSION}

Sevoflurane was found to be associated with less changes in hemodynamic parameters as compared to propofol but quality of intubation conditions was poor using sevoflurane. Propofol is a better drug as compared to sevoflurane for providing better intubation conditions.

\section{CONFLICT OF INTEREST}

This study has no conflict of interest to be declared by any author.

\section{REFERENCES}

1. Tran DT, Newton EK, Mount VA, Lee JS, Wells GA, Perry JJ. Rocuronium versus succinylcholine for rapid sequence induction intubation. Cochrane Database Syst Rev 2015; (10): CD002788.

2. Thompson GC, Lang E, Powelson S, Wakai A, Vandermeer B, O'Sullivan R, et al. Atropine therapy versus no atropine therapy for the prevention of adverse events in paediatric patients undergoing intubation. Cochrane Database Syst Rev 2018; 2018(1): CD010898.

3. Stambolija V, Stambolija TP, Holjevac JK, Murselovic T, Radonic J, Duzel V. BPC 157: the counteraction of succinylcholine, hyperkalemia, and arrhythmias. Eur J Pharmacol 2016; 781: 83-91.

4. Singh S, Malviya D, Rai S, Yadav B, Kumar S, Sharma A. Pretreatment with magnesium sulphate before non-depolarizing muscle relaxants: effect on speed on onset, induction and recovery. Int J Med Sci Public Health 2014; 3(10): 1238-44.

5. Chidambaran V, Costandi A, D'Mello A. Propofol: a review of its role in pediatric anesthesia and sedation. CNS Drugs 2015; 29(7): 543-63.

6. Campus NH. Tracheal intubation in children using sevoflurane without muscle relaxant. A novel approach using apnea as clinical indicator. Ped Anesth Crit Care J 2015; 3(1): 53-60.

7. Rajan S, Gotluru P, Andews S, Paul J. Evaluation of endotracheal intubating conditions without the use of muscle relaxants following induction with propofol and sevoflurane in pediatric cleft lip and palate surgeries. J Anaesth Clin Pharmacol 2014; 30(3): 360-65.

8. Raghavendra T, Yoganarasimha N, Radha M, Madhu R. A clinical study to compare the ease of intubation with combination of sevoflurane and propofol with propofol alone. Innovat J Med Health Sci 2013; 3(3): 143-48. 
9. Darji V, Panjabi G. A comparison of sevoflurane versus propofol for tracheal intubation in children. NHL J Med Sci 2014; 3(2): 1-3.

10. Thwaites AJ, Edmends S, Tomlinson AA, Kendall JB, Smith I. Double-blind comparison of sevofluran vs propofol and succinylcholine for tracheal intubation in children. Br J Anaesth 1999; 83(3): 410-14.

11. Page E, Alston P. Does the end-tidal concentration of inhalational anaesthetics accurately estimate blood concentration during onelung ventilation? J Cardiothorac Vasc Anesth 2017; 31: S56-S7.

12. Dennhardt N, Arndt S, Beck C, Boethig D, Heiderich S, Schultz B, et al. Effect of age on narcotrend index monitoring during sevoflurane anesthesia in children below 2 years of age. Pediatr Anesth 2018; 28(2): 112-19.

13. Rhondali O, Pouyau A, Mahr A, Juhel S, De Queiroz M, Rhzioual-Berrada K, et al. Sevoflurane anesthesia and brain perfusion. Pediatr Anesth 2015; 25(2): 180-85.

14. Inomata $S$, Watanabe $S$, Taguchi M. End-tidal sevof-lurane concentration for tracheal intubation and minimum alveolar con- centration in pediatric patients. Anesthesiol 1994; 80(1): 93-96.

15. Simons JC, Pierce E, Diaz-Gil D, Malviya SA, Meyer MJ, Timm $\mathrm{FP}$, et al. Effects of Depth of propofol and sevoflurane anesthesia on upper airway collapsibility, respiratory genioglossus activation, and breathing in healthy volunteers. Anesthesiology 2016; 125(3): 525-34.

16. Kumar AK, Rao KP, Rajasekhar M, Praveena A, Sindhuja J, Ramchandran G. The haemodynamic effects of thiopentone/propofol and combined use of low dose thiopentone and propofol on induction and intubation-a three modality comparative study. J Contemp Med Res 2018; 5(7): G4-G10.

17. Reddy RK, Rao GP. A clinical study of comparison of combination of sevoflurane and propofol with propofol alone for induction and intubation. Indian J Appl Res 2015; 5(8): 368-73.

18. Viitanen $H$, Tarkkila $P$, Mennander S, Viitanen $M$, Annila P. Sevoflurane-maintained anesthesia induced with propofol or sevoflurane in small children: induction and recovery characteristics. Can J Anesth 1999; 46(1): 21-28. 